\title{
Editorial
}

\section{Dimensões de sexo, gênero e raça na pesquisa sobre COVID-19}

doi: 10.5123/S1679-49742020000300023

\author{
Sex, gender and race dimensions in COVID-19 research
}

Dimensiones del sexo, género y raza en la investigación sobre COVID-19

COVID-19, doença que emergiu na China, no final de 2019, rapidamente se espalhou pelos cinco continentes e
foi declarada pandemia pela Organização Mundial da Saúde (OMS), em 11 de março de 2020.0 enfrentamento
desta doença totalmente nova demanda a produção de conhecimento epidemiológico e clínico, assim como o desenvolvimento de testes diagnósticos, tratamentos e vacinas. Nesse contexto, a pesquisa e o desenvolvimento tecnológico devem ser priorizados, assim como a rápida divulgação de seus resultados. ${ }^{1}$

A literatura científica relacionada à COVID-19 apresentou crescimento exponencial, acompanhando a evolução do número de casos e óbitos pela doença no mundo. De janeiro a meados de maio de 2020, a literatura sobre COVID-19 incluiu 31 mil artigos, e se aproximou de 50 mil na metade de junho. ${ }^{2}$

Contudo, pesquisas sobre a COVID-19 que incorporem a perspectiva de sexo, gênero e raça são escassas, apesar das evidências de que estas características desempenham papel expressivo na conformação dos riscos de doença, morte e outros danos associados. Iniciativas internacionais, como a liderada pela organização GENDR0, chamam a atenção para esse fato, e clamam por um compromisso renovado com a pesquisa sensível ao gênero e a outras dimensões de desigualdade para a equidade em saúde e os direitos humanos no contexto da pandemia da COVID-19. ${ }^{3}$ Tais iniciativas alinham-se às diretrizes sobre Equidade de Sexo e Gênero em Pesquisa (Sex and Gender Equity in Research - SAGER) que, entre outros aspectos, enfatizam o papel de todos os envolvidos na pesquisa e na publicação científica - incluindo-se pesquisadores, editores, revisores e financiadores - para a promoção da equidade, em benefício de toda a sociedade. ${ }^{4,5}$

Ademais, estudos têm evidenciado o acirramento das desigualdades de sexo e gênero na pesquisa e na publicação científica no contexto da pandemia. Em periódicos médicos, foi observada baixa representação de mulheres como primeiras autoras de artigos sobre COVID-19 publicados em março e abril de 2020. ${ }^{6}$ Nesses meses, autoras do sexo feminino publicaram menos artigos nos servidores de preprints, em comparação ao mesmo período do ano anterior, ${ }^{7}$ e o número de autores do sexo masculino cresceu mais rapidamente que do feminino. ${ }^{8}$ Além das causas preexistentes de tais desigualdades, principalmente relacionadas ao sexismo, tem sido relatada menor dedicação das mulheres ao desenvolvimento de suas pesquisas, em decorrência do aumento do tempo com a realização de atividades domésticas e de cuidado durante 0 isolamento, especialmente entre as mulheres que têm filhos em casa. ${ }^{9}$

A raça/cor da pele de pesquisadores e autores não é facilmente identificável a partir das informações publicadas nos artigos. Todavia, é conhecida a sub-representação da população negra e o racismo na ciência. ${ }^{10}$ Tal situação tem sido evidenciada na onda de protestos contra 0 racismo em resposta às mortes de homens negros por policiais nos Estados Unidos, em junho de 2020. ${ }^{11}$ É importante reconhecer que as mulheres negras enfrentam desafios ainda maiores e desenvolver ações estruturais que apoiem sua participação na pesquisa e na publicação científica. ${ }^{9}$

A participação limitada de mulheres e de pessoas negras na condução de pesquisas sobre a COVID-19 pode alterar a ênfase em aspectos relevantes para populações específicas. ${ }^{7}$ Garantir sua presença é fundamental para 0 enfrentamento à pandemia, uma vez que tais minorias na academia relatam, com maior frequência, resultados de pesquisa desagregados por sexo, gênero e raça. Isso contribui para melhorar a compreensão dos aspectos clínicos e epidemiológicos da COVID-19, particularmente face a evidências de disparidades segundo sexo e raça na incidência, na mortalidade e nos impactos socioeconômicos da doença. ${ }^{12}$ 
0 Brasil é um país marcado por grandes iniquidades sociais e regionais, que se sobrepõem a desigualdades no acesso aos serviços de saúde. Nesse contexto, é ainda mais importante investigar aspectos da pandemia que possam levar ao recrudescimento das disparidades existentes. A Epidemiologia e Serviços de Saúde: revista do Sistema Único de Saúde do Brasil reitera seu compromisso com a equidade de sexo, gênero e raça na pesquisa e na publicação científica, reforçando que as pesquisas clínicas e epidemiológicas sobre a COVID-19, assim como aquelas sobre o impacto social, econômico e de direitos humanos da pandemia, devam ser desenhadas, conduzidas e relatadas de modo a se considerarem sistematicamente o sexo, o gênero, a raça e outras dimensões de desigualdade.

Leila Posenato Garcia' ${ }^{1}$ - (1) orcid.org/0000-0003-1146-2641

${ }^{1}$ Instituto de Pesquisa Econômica Aplicada, Diretoria de Estudos e Políticas Sociais, Brasília, DF, Brasil

\section{Referências}

1. Oliveira WK, Duarte E, França GV, Garcia LP. Como o Brasil pode deter a COVID-19. Epidemiol Serv Saúde [Internet]. 2020 abr [citado 2020 jun 20];29(2):e2020044. Disponível em: https://doi.org/10.5123/s1679-49742020000200023

2. Brainard J. New tools aim to tame pandemic paper tsunami. Science [Internet]. 2020 May [cited 2020 jun 20];368(6494):9245. Available from: https://doi.org/10.1126/science.368.6494.924

3. Advancing Sex and Gender Equity in Research - GENDRO. A call for urgent action: a renewed commitment to gender responsive research for health equity and human rights in the context of COVID-19 pandemic [Internet]. [S.1.]: Advancing Sex and Gender Equity in Research; 2019 [cited 2020 Jun 20]. Available from: https:/www.gendro.org/statements

4. Heidari S, Babor TF, Castro P, Tort S, Curno M. Equidade de sexo e gênero na pesquisa: fundamentação das diretrizes SAGER e uso recomendado. Epidemiol Serv Saúde [Internet]. 2017 jul-set [citado 2020 jun 20];26(3):665-76. Disponível em: https:// doi.org/10.5123/s1679-49742017000300025.

5. Garcia LP, Duarte E. Equidade de sexo e gênero na pesquisa e na publicação científica. Epidemiol Serv Saúde [Internet]. 2017 jul-set [citado 2020 jun 20];26(3):431-2. Disponível em: https://doi.org/10.5123/s1679-49742017000300001

6. Andersen JP, Nielsen MW, Simone NL, Lewiss RE, Jagsi R. Meta-research: COVID-19 medical papers have fewer women first authors than expected. eLife [Internet]. 2020 May [cited 2020 Jun 20]. Available from: https://doi.org/10.7554/eLife.58807

7. Vincent-Lamarre P, Sugimoto CR, Lariviere V. The decline of women's research production during the coronavirus pandemic. Nature Index [Internet]. 2020 May [cited 2020 Jun 20]. Available from: https://www.natureindex.com/news-blog/declinewomen-scientist-research-publishing-production-coronavirus-pandemic

8. Frederickson M. COVID-19's gendered impact on academic productivity [Internet]. 2020 May [cited 2020 Jun 20]. Available from: https://github.com/drfreder/pandemic-pub-bias

9. Gabster BP, von Daalen K, Dhatt R, Barry M. Challenges for the female academic during the COVID-19 pandemic. Lancet [Internet]. 2020 Jun [cited 2020 Jun 20]. Available from: https://doi.org/10.1016/S0140-6736(20)31412-4

10. The Cell editorial team. Science has a racism problem. Cell [Internet]. 2020 Jun [cited 2020 Jun 20]. Available from: https:// doi.org/10.1016/ j.cell.2020.06.009

11. Subbaraman N. Grieving and frustrated: black scientists call out racism in the wake of police killings. Nature [Internet]. 2020 Jun [cited 2020 Jun 20]. Available from: https://www.nature.com/articles/d41586-020-01705-X

12. Pinho-Gomes AC, Peters S, Thompson K, Hockham C, Ripullone K, Woodward M, et al. Where are the women? Gender inequalities in COVID-19 research authorship. BMJ Glob Health [Internet]. 2020 [cited 2020 Jun 20];5(7):e002922. Available from: https://doi.org/10.1136/bmjgh-2020-002922 https://gh.bmj.com/content/bmjgh/5/7/e002922.full.pdf 